\section{ACOUSTICS AND BEYOND.}

Hyperacoustics. By J. L. Dunk. Division i., Simultaneous Tonality. Pp. vit+3Ir. (London: J. M. Dent and Sons, Ltd., I9r6.) Price $7 s .6 d$. net.

THE title of the work of which the present volume is but the first division is thus dealt with in the preface: "Between the region of phenomena [undefined] comprised in the science of acoustics, and the experiences of music considered as phenomena, there appears a great gulf, which invites attempts to bridge." "The "gulf" has two sides, and can be approached either by working forward from the material aspect of acoustics, or backward from the experiential aspects of music. However, in the present investigation it is the purely scientific side that is emphatically insisted upon. Hence the name 'Hyperacoustics' may be proposed, as indicative not only of something beyond, but also of a presumption requiring justification as to the existence and rationality of something beyond the known facts of acoustics."

It is held that the subject may be considered under the divisions Tonality, Rhythm, Organisation, and Significance. The present volume is restricted to the aspect of "Tonality," the science of musical sound in pitch and quality.

As to the treatment of the subject, whenever incidental references are made to the various intervals, whether in the just or equally tempered intonations, the author shows an accurate knowledge of the facts. But, immediately he steps beyond the facts themselves to any discussion of them, all seems on a different plane-a plane of pure fancy, or " hyperscience."

This treatment might conceivably exercise some fascination over certain minds inclined to the occult and esoteric; and in such matters the mere man of science is not competent to judge. It may be that a feeling of shrinking on the part of the ordinary reader is inevitable towards a work designed to bridge in this wise the gulf between physics and music. But, without doubt, the work is quite lacking in all appeal to either the physicist or the musician. Indeed, the scientific reader cannot help wondering whither it all tends or what it is supposed to establish. Every few pages sees the introduction of one or more terms of a strange character and vague import. These are then woven into the discussion, which again continues without any apparent advance.

One of the simplest and least fanciful parts of the work is that in which the intervals are likened to colours. Thus the perfect fourth is regarded as red, the major third as green, and the minor third as violet. Then, by composition, are obtained the following. The perfect fifth is green plus violet equals blue, the minor sixth is red plus violet equals mauve, the major sixth is red plus green equals yellow. Again, the octave is red plus green plus violet equals white, and the unison is zero equals black.

An illustration of the more general style of NO. 2460 , VOL. 98$]$ the work is afforded by the following quotation (p. 22I) :-

"The fact that, acoustically, the Seriopolar aspect of the Matrix is only effective in the Fundamental Species, and that the approximation of the Tensor Heptad to the Hemicyclic type is nearer than the Laxator. Heptad, is evidently responsible for the recognition of a distinct chiral bias in progression denoted at an early date by the word "Authentic." "

\section{MORPHOLOGY: OLD AND NEW.}

Form and Function: a Contribution to the History of Animal Morphology. By E. S. Russell.

Pp. ix +383 . (London: John Murray, I916.) Price ros. $6 d$. net.

A SCHOLARLY and thoughtful book like this 1 makes one feel how much is lost to students of biology by lack of attention to the historical development of the science. Not only is the human interest missed, but also the educativeness of tracing the history of fundamental ideas. Moreover, for lack of historical discipline, the same mistakes. are made over and over again, and sound generalisations which have ceased to be prominent are unconsciously restated as new, it may be in a form far inferior to that given them by Cuvier, E. Geoffroy Saint-Hilaire, von Baer, or some other outstanding thinker of older days. We welcome, therefore, Mr. Russell's contribution to the history of morphology, for it is based on many years of first-hand study of the documents and is illumined by insight. It is true history, not chronicle; it displays the continuous endeavour from Aristotle until to-day to understand the forms of animals, both in their original establishment and in their individual reproduction in every lifecycle.

The author distinguishes three main currents of morphological thought. The first he calls "functional or synthetic," which interprets form as the manifestation of function or activity. It is "associated with the great names of Aristotle, Cuvier, and von Baer, and leads easily to the more open vitalism of Lamarck and Samuel Butler." The second he calls "formal or transcendental," which regards function as the result of form-the outcome of organisation. "The typical representative of the second attitude is E. Geoffroy Saint-Hilaire, and this habit of thought has greatly influenced the development of evolutionary morphology." "The third he calls "materialistic or disintegrative," which was greatly influenced by the cell-theory.

The author's general position is with the morphologists of the first school; he believes that attention should be concentrated "on the active response of the animal, as manifested both in behaviour and in morphogenesis, particularly in the post-embryonic stages." He frankly adopts "the simple everyday conception of living things -which many of us have had drilled out of usthat they are active, purposeful agents, not mere complicated aggregations of protein and other substances." 